\title{
Association between vertebral fractures and coronary artery calcification in current and former smokers in the ECLIPSE cohort
}

\author{
M. J. vanDort ${ }^{1}$ (D) J. H. M. Driessen ${ }^{1,3,4}$ • P. Geusens ${ }^{2}$ • E. A. P. M. Romme ${ }^{5}$ - F. W. J. M. Smeenk ${ }^{5,6}$ • B. M. Rahel ${ }^{7}$. \\ J. A. Eisman ${ }^{3,8,9,10,11}$ • E. F. M. Wouters ${ }^{1,12}$ - J. P. W. van den Bergh ${ }^{1,13}$
}

Received: 2 November 2018 / Accepted: 30 October 2019 / Published online: 25 November 2019

(C) The Author(s) 2019

\begin{abstract}
Summary In smokers and former smokers from the ECLIPSE cohort, there is an association between prevalent vertebral fractures (VFs) and coronary artery calcification (CAC). Chest CT scans provide the opportunity to evaluate VFs and CAC, which are potentially important comorbidities, each of which is amenable to effective interventions.

Introduction Prevalence of VFs among smokers and patients with chronic obstructive pulmonary disease (COPD) is high, and an association between CAC and osteoporosis has been described. We investigated the associations between VFs and CAC (expressed in Agatston score) in (former) smokers.

Methods Current and former smokers from the ECLIPSE study (designed to determine underlying COPD progression mechanisms) were studied. Baseline Agatston score (zero (0), medium (1-400), or high (> 400)), baseline bone attenuation (BA), and prevalent and incident VFs (vertebrae $\mathrm{T}_{1}-\mathrm{L}_{1}$ ) were assessed on CT.

Results A total of 586 subjects were included (mean age $59.8 \pm 8.3 ; 62.3 \%$ men; $70.1 \%$ with COPD; $21.0 \%$ with prevalent VFs; 196 with zero, 266 with medium, and 124 with high Agatston score). Of these, $23.4 \%$ suffered incident VFs within 3 years. In multivariate models, prevalent VFs were associated with medium (1.83 [95\% CI 1.01-3.30]) and with high (OR = 3.06 [1.456.47]) Agatston score. After adjustment for BA, prevalent VFs were still associated with high (OR = 2.47 [1.13-5.40]), but not significantly with medium Agatston score (OR = 1.57 [0.85-2.88]). Similarly, after adjustment for BA, high $(\mathrm{OR}=2.06[1.02-$ 4.13]) but not medium Agatston score $(\mathrm{OR}=1.61$ [0.88-2.94]) was associated with prevalent VFs. Agatston score at baseline was not associated with short-term VF incidence.
\end{abstract}

Electronic supplementary material The online version of this article (https://doi.org/10.1007/s00198-019-05218-w) contains supplementary material, which is available to authorized users.

M. J. van Dort

m.vandort@maastrichtuniversity.nl

$1 \quad$ NUTRIM School of Nutrition and Translational Research in Metabolism, Maastricht University Medical Centre+ (MUMC+), Maastricht, The Netherlands

2 Department of Internal Medicine, Rheumatology, Maastricht University Medical Centre+ (MUMC+),

Maastricht, The Netherlands

3 CAPHRI Care and Public Health Research Institute, Maastricht University Medical Centre+ (MUMC+), Maastricht, The Netherlands

4 Department of Clinical Pharmacy and Toxicology, Maastricht University Medical Centre+ (MUMC+),

Maastricht, The Netherlands

5 Department of Respiratory Medicine, Catharina Hospital, Eindhoven, the Netherlands
6 School of Health Professions Education, Faculty of Health Medicine and Life Sciences, Maastricht University Medical Centre+ (MUMC+), Maastricht, The Netherlands

7 Department of Cardiology, VieCuri Medical Centre, Venlo, The Netherlands

8 Department of Endocrinology, St Vincent's Hospital, Sydney, Australia

9 Garvan Institute of Medical Research, Sydney, Australia

10 School of Medicine Sydney, University of Notre Dame, Sydney, Australia

11 University of New South Wales (UNSW Sydney), Sydney, Australia

12 Department of Respiratory Diseases, Maastricht University Medical Centre+ (MUMC+), Maastricht, The Netherlands

13 Department of Internal Medicine, VieCuri Medical Centre, Venlo, The Netherlands 
Conclusion In (former) smokers, there was an association between prevalent VFs and Agatston score. Chest CT scans provide the opportunity to also evaluate for VFs and CAC, which are potentially important comorbidities, each of which is amenable to effective interventions.

Keywords Agatston score $\cdot$ Comorbidity $\cdot$ COPD $\cdot$ Coronary artery calcification $\cdot$ Smoking $\cdot$ Vertebral fracture

\section{Introduction}

Reported prevalence of vertebral fractures (VFs) among smokers and COPD patients is high (9-79\% [1-7]) and, in the international ECLIPSE (Evaluation of COPD Longitudinally to Identify Predictive Surrogate Endpoints) cohort, we previously reported that shortterm incidence of VFs is high in smokers and former smokers with one or more prevalent VF [8]. A recent review described an association between cardiovascular disease (CVD) and osteoporosis [9] and suggested the potential benefits from routine bone assessment in patients with CVD. Associations between emphysema and osteoporosis or bone density have also reported [4, 10, 11]. An association between emphysema and coronary artery calcification (CAC) has been reported in some studies [12,13] but not in others [14-16].

Although CAC itself may be clinically asymptomatic, it is associated with coronary heart disease in patients without known CHD [17-19], cardiovascular disease [20], cardiac events [21], and mortality [22-24]. Also, in a population of (former) smokers (National Lung Screening Trial (USA)), CAC was associated with CHD death and all-cause mortality [25]. Calcification in the coronary arteries is related to the underlying plaque burden, and calcifications in the coronary arteries, aortic arch, and carotid arteries are correlated (moderate to strong) [26].

Chest CT scans are regularly performed to evaluate pulmonary disease and can be used to diagnose emphysema. Additionally, CT scans give the opportunity to evaluate the bone status (bone attenuation (BA) and VFs) and CAC (expressed in Agatston score).

Therefore, the aim of this study was to evaluate the associations between variables measured on chest $\mathrm{CT}$ scans in current or former smokers from the ECLIPSE cohort:

a) The association between prevalent VFs and baseline Agatston score

b) The association between baseline Agatston score and prevalent VFs

c) The association between baseline Agatston score and incident VFs within 1 and 3 years

\section{Methods}

\section{Subjects}

The ECLIPSE (Evaluation of COPD Longitudinally to Identify Predictive Surrogate Endpoints) study is a noninterventional multicenter study that was started to search underlying mechanisms of disease progression in subjects with COPD and to identify biomarkers that may serve as surrogate endpoints and measures of disease progression (Clinicaltrials. gov identifier NCT00292552; GlaxoSmithKline study SCO104960).

Detailed inclusion and exclusion criteria were described elsewhere [27-29]. In brief, current or former smokers (4075 years old) with moderate to very severe COPD (Global Initiative for Chronic Obstructive Lung Disease (GOLD) stages II-IV) or without COPD, with a smoking history of at least 10 pack years, were included. Subjects with respiratory diseases other than COPD, patients with $\alpha 1$-antitrypsin deficiency, with known history of significant inflammatory disease other than COPD, with an exacerbation requiring treatment within 4 weeks prior to enrolment, or subjects who used oral glucocorticosteroids (GC) at baseline were excluded.

\section{Measurements}

Demographic and pulmonary information were collected as well as number of pack years and smoking status. Detailed information can be found elsewhere [27-29].

CT scans were performed at full inspiration $(120 \mathrm{kV}$ peak, $40 \mathrm{mAs}, 1.00$ or $1.25-\mathrm{mm}$ volumetric acquisition, General Electric or Siemens), at baseline, 1-year, and 3-year followup. CT scanners were calibrated regularly using industry and institutional standards. Emphysema, VFs, BA, and Agatston score were measured on these CT scans.

Emphysema was measured as \% low attenuation area (\%LAA), as described by Coxson et al. [30]. The presence of emphysema was defined by a cutoff value of $>10 \%$ LAA [30].

Sagittal reformats containing the spine were superposed to create simulated lateral X-ray images. VFs from $\mathrm{T}_{1}$ to $\mathrm{L}_{1}$ were semi-quantitatively and subsequently quantitatively (using SpineAnalyzer Morphometry software; Optasia Medical, Cheadle, UK [31-33]) assessed on the 3-year follow-up images. VFs were classified according to the method by Genant 
et al. as grade 1 (mild), grade 2 (moderate), or grade 3 (severe) [34]. If VFs were diagnosed on the 3-year scan, the 1-year scan was morphometrically assessed. If VFs were diagnosed on the 1-year scan, the baseline scan was also evaluated. Incident VFs were defined as new (no VF to any grade of VF) or worsening VFs (increase in grade of VF) as previously described [8].

BA was measured semi-automatically in cubic areas of approximately $275 \mathrm{~mm}^{3}$ (slightly varying due to different voxel sizes between scanners) centered in vertebrae $T_{4}-T_{12}$. Mean BA of vertebrae $T_{4}-T_{12}$ was expressed in Hounsfield units (HU). Vertebrae that were fractured (grade 1 or higher [34]) or that showed other abnormalities were excluded from BA measurements.

Agatston score measurements are described in detail elsewhere $[15,35]$. Areas of $\geq 1 \mathrm{~mm}^{3}$ with a threshold of $\geq 130$ $\mathrm{HU}$ in the course of a coronary artery were considered CAC. Agatston score was calculated as the sum of weighted areas (depending on peak attenuation within the area) on axial slices. Three groups were made based on Agatston score at baseline: zero (0 Agatston units (AU)), medium (1-400 AU), or high Agatston score (> $400 \mathrm{AU})$.

\section{Main outcome measure}

The main outcome measures were

a) Prevalent Agatston score (main factor: prevalent VFs)

b) Prevalent VFs (main factor: prevalent Agatston score)

c) Incident VFs within 1 and 3 years (main factor: prevalent Agatston score)

Possible confounders that were considered included age; sex; BMI; smoking status (current/former); number of pack years; presence of COPD; emphysema (> 10\%LAA); and in case of incident VFs, prevalent VFs at baseline. Since associations between BA and Agatston score [36] and between BA and fractures $[1,37]$ have been reported, BA was included as a potential confounder.

\section{Statistics}

a) Association between prevalent VFs and baseline Agatston score

A chi-square test was used to compare the proportion of patients with a prevalent VF between the Agatston score groups. Logistic regression models (SAS 9.3, SAS Institute, Cary, NC, USA; LOGISTIC procedure) were used to evaluate the association between prevalent VFs (no VF, or $\geq 1 \mathrm{VF}$ ) and Agatston score group (zero $0 \mathrm{AU}$, medium 1-400 AU, or high $>400 \mathrm{AU})$. To compare medium vs zero Agatston score group, only subjects with medium or zero Agatston score were included in the analyses. To compare high vs zero Agatston score, only subjects with high or zero Agatston score were included.

b) Association between baseline Agatston score and prevalent VFs

To evaluate the association between Agatston score and prevalent VFs, logistic regression models including all subjects were used.

c) Association between Agatston score and incident VFs within 1 and 3 years

A chi-square test was used to compare the proportion of patients with an incident VF between the Agatston score groups. To evaluate the association between Agatston score and incident VFs, Cox proportional hazard models were used (PHREG procedure). When incident VFs were expressed in numbers of incident VFs $(0,1$, or $\geq 2)$, a nominal regression model was used (LOGISTIC procedure).

\section{Confounders}

Age, sex, and presence of COPD were included in all multivariate models; other confounders were included in the multivariate model if they independently changed the beta-coefficient of the main exposure ((a) prevalent VFs; (b) Agatston score group; (c) incident VFs) by $5 \%$ or more, or previously reported associations indicated that they should be included.

Odds ratios (ORs) and hazard ratios (HRs) are given with 95\% CI. Subjects with complete availability of VF assessment and Agatston score evaluation were selected. Only 1 subject $(0.2 \%)$ had missing data and was excluded from further analyses.

\section{Results}

Out of a total of 2298 ECLIPSE subjects (327 subjects without and 1971 with COPD), there were 586 subjects (411 with and 175 without COPD) with Agatston score and VF assessment available (Table 1) [8]. Of the patients with a zero Agatston score, $20(10.2 \%)$ had one or more prevalent VFs, compared to $61(22.9 \%)$ in the medium Agatston score group and 42 (33.9\%) in the high Agatston score group (Fig. 1). The proportion of patients with a prevalent VF was significantly different across the Agatston score groups ( $p$ value $<0.001$ ). Of the patients with a zero Agatston score, $40(20.4 \%)$ had one or more incident VFs within 3 years, compared to $60(22.6 \%)$ in the medium Agatston score group and 37 (29.8\%) in the high Agatston score group. The proportion of patients with an 
Table 1 Baseline characteristics

\begin{tabular}{|c|c|c|c|c|c|c|c|c|}
\hline \multirow{3}{*}{ Age (years: mean, sd) } & \multirow{2}{*}{\multicolumn{2}{|c|}{$\begin{array}{l}\text { All subjects } \\
n=586\end{array}$}} & \multirow{2}{*}{\multicolumn{2}{|c|}{$\begin{array}{l}\text { Zero Agatston group } \\
n=196\end{array}$}} & \multirow{2}{*}{\multicolumn{2}{|c|}{$\begin{array}{l}\text { Medium Agatston group } \\
n=266\end{array}$}} & \multirow{2}{*}{\multicolumn{2}{|c|}{$\begin{array}{l}\text { High Agatston group } \\
n=124\end{array}$}} \\
\hline & & & & & & & & \\
\hline & 59.8 & 8.3 & 55.0 & 7.6 & 60.8 & 7.7 & 65.3 & 6.1 \\
\hline Sex (M: $n, \%)$ & 365 & 62.3 & 93 & 47.4 & 176 & 66.2 & 96 & 77.4 \\
\hline BMI $\left(\mathrm{kg} / \mathrm{m}^{2}:\right.$ mean, sd $)$ & 26.1 & 4.3 & 26.0 & 4.6 & 26.2 & 4.0 & 26.0 & 4.2 \\
\hline With COPD $(n, \%)$ & 411 & 70.1 & 106 & 54.1 & 200 & 75.2 & 105 & 84.7 \\
\hline Current smoker $(n, \%)$ & 275 & 46.9 & 111 & 56.6 & 115 & 43.2 & 49 & 39.5 \\
\hline Pack years (mean, sd) & 41.1 & 24.0 & 32.8 & 18.8 & 44.1 & 24.8 & 47.6 & 26.2 \\
\hline Emphysema $>10 \%$ LAA $(n, \%)$ & 263 & 44.9 & 66 & 33.7 & 130 & 48.9 & 67 & 54.0 \\
\hline Bone attenuation (HU: mean, sd) & 158.4 & 46.5 & 174.9 & 43.4 & 154.0 & 42.6 & 141.5 & 51.2 \\
\hline$\geq 1$ prevalent $\mathrm{VF}(n, \%)$ & 123 & 21.0 & 20 & 10.2 & 61 & 22.9 & 42 & 33.9 \\
\hline Incident VF within 1 year $(n, \%)$ & 57 & 9.7 & 14 & 7.1 & 22 & 8.3 & 21 & 16.9 \\
\hline Incident VF within 3 years $(n, \%)$ & 137 & 23.4 & 40 & 20.4 & 60 & 22.6 & 37 & 29.8 \\
\hline
\end{tabular}

Baseline characteristics for all subjects and by Agatston score group. Zero 0 Agatston units (AU); medium 1-400 AU; high > $400 \mathrm{AU}$

$B M I$ body mass index, $C O P D$ chronic obstructive pulmonary disease, $\% L A A \%$ low attenuation area, $H U$ Hounsfield units, $V F$ vertebral fracture

incident VF over 3 years increased (but not significantly) across the Agatston score groups ( $p$ value 0.14 ).

\section{Association between prevalent VFs and baseline Agatston score}

Of the subjects with one or more prevalent VF, 20 (16\%) had zero Agatston score, 61 (50\%) had medium Agatston score, and $42(34 \%)$ had high Agatston score. In subjects without prevalent VFs, these numbers were 176 (38\%), 205 (44\%), and $82(18 \%)$ respectively (Supplemental Figure 1).

In univariate models, subjects with prevalent VFs had higher odds of a medium (OR 2.62 [1.52-4.51]) or high Agatston score (OR 4.51 [2.49-8.16]) compared to subjects without VFs (Table 2). In multivariate models, subjects with prevalent VFs had higher odds of having a medium (1.83 [95\% CI 1.009-3.304]) or high (OR = 3.06 [1.450-6.473]) Agatston score compared to subjects without VFs. After additional adjustment for BA, subjects with prevalent VFs still had higher odds of high $(\mathrm{OR}=2.37$ [1.06-5.31]), but not of medium Agatston score $(\mathrm{OR}=1.56$ [0.84-2.90]).
In univariate models, odds of medium or high Agatston score for subjects with emphysema (> 10\%LAA) were 1.88 [1.29-2.76], but this was not significant after adjustment for age and sex.

\section{Association between baseline Agatston score and prevalent VFs}

Characteristics of subjects with $(n=123)$ or without $(n=463)$ prevalent VFs are given in Table 3. In univariate models, subjects with medium (2.62 [1.52-4.51]) or high Agatston score (4.51 [2.49-8.16]) had higher odds of having a prevalent VF compared to subjects with a zero Agatston score. In multivariate models, subjects with medium $(\mathrm{OR}=1.91$ [1.07$3.40])$ or high Agatston score $(\mathrm{OR}=2.71[1.40-5.26])$ had significantly increased odds of having a prevalent VF compared to subjects with a zero score. After additional adjustment for BA, subjects with high but not medium Agatston score had significantly higher odds of prevalent VFs than subjects with a zero score $(\mathrm{OR}=2.03[1.01-4.08]$ and $\mathrm{OR}=$ 1.60 [0.88-2.92] respectively; Table 3).

Fig. 1 Proportion of patients with a prevalent VF (left panel) or 1- or 3 -year incident VF (right panel) stratified by Agatston score. AU Agatston units, VF vertebral fracture

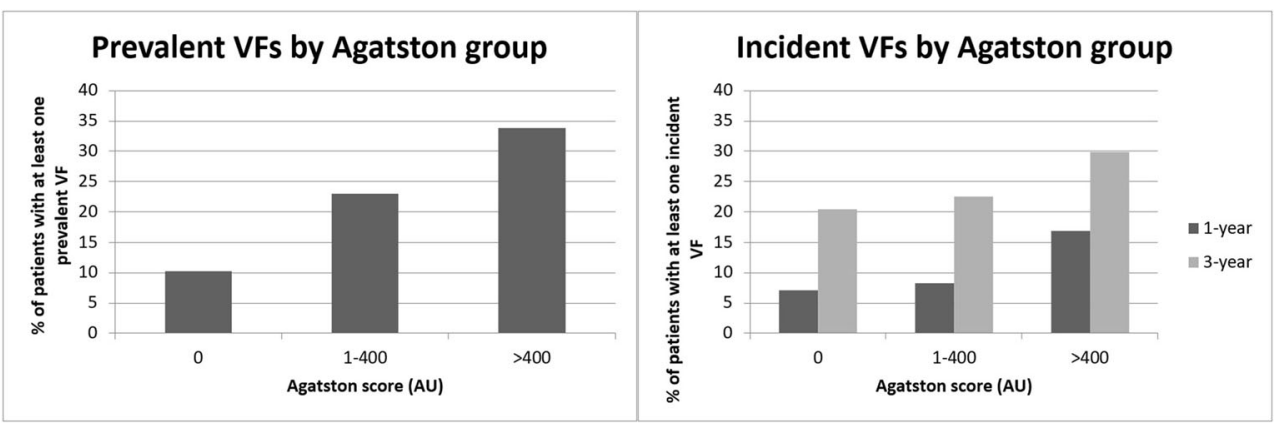


Table 2 Association between prevalent VFs and Agatston score

\begin{tabular}{|c|c|c|c|c|c|c|}
\hline & \multicolumn{2}{|c|}{ Univariate } & \multicolumn{2}{|c|}{ Multivariate, without BA } & \multicolumn{2}{|c|}{ Multivariate, with BA } \\
\hline & OR & $95 \% \mathrm{CI}$ & OR & $95 \% \mathrm{CI}$ & OR & $95 \% \mathrm{CI}$ \\
\hline \multicolumn{7}{|l|}{ Medium Agatston score } \\
\hline Age (per +8 years) & 2.16 & {$[1.750-2.654]$} & 1.84 & {$[1.446-2.332]$} & 1.67 & [1.296-2.150] \\
\hline $\operatorname{Sex}(M v s F)$ & 2.17 & [1.484-3.162] & 1.79 & {$[1.183-2.703]$} & 1.85 & [1.220-2.808] \\
\hline $\mathrm{BMI}\left(\right.$ per $\left.+4 \mathrm{~kg} / \mathrm{m}^{2}\right)$ & 1.05 & {$[0.879-1.243]$} & - & & - & \\
\hline Current smoker (vs former) & 0.58 & {$[0.402-0.846]$} & - & & - & \\
\hline Pack years (per +24 pack years) & 1.95 & [1.502-2.537] & 1.37 & {$[1.041-1.791]$} & 1.39 & [1.060-1.828] \\
\hline COPD (vs no COPD) & 2.57 & [1.733-3.821] & 1.26 & {$[0.781-2.030]$} & 1.27 & {$[0.788-2.062]$} \\
\hline $\mathrm{BA}($ per $-46 \mathrm{HU})$ & 1.68 & [1.367-2.072] & - & & 1.30 & [1.024-1.664] \\
\hline$\geq 1$ prevalent VF (vs none) & 2.62 & {$[1.520-4.510]$} & 1.83 & {$[1.009-3.304]$} & 1.57 & {$[0.853-2.883]$} \\
\hline Emphysema (vs “no emphysema”) & 1.88 & {$[1.286-2.757]$} & - & & - & \\
\hline \multicolumn{7}{|l|}{ High Agatston score } \\
\hline Age (per +8 years $)$ & 4.81 & [3.373-6.854] & 3.97 & {$[2.718-5.809]$} & 3.69 & {$[2.512-5.412]$} \\
\hline Sex (M vs F) & 3.80 & {$[2.290-6.297]$} & 2.75 & {$[1.473-5.118]$} & 3.08 & [1.616-5.885] \\
\hline BMI (per +4 kg/m²) & 1.01 & {$[0.828-1.241]$} & - & & - & \\
\hline Current smoker (vs former) & 0.50 & {$[0.317-0.791]$} & - & & - & \\
\hline Pack years (per + 24 pack years) & 2.17 & [1.610-2.914] & 1.60 & {$[1.124-2.272]$} & 1.57 & [1.099-2.237] \\
\hline COPD (vs no COPD) & 4.69 & {$[2.670-8.244]$} & 1.39 & {$[0.665-2.916]$} & 1.38 & {$[0.657-2.886]$} \\
\hline $\mathrm{BA}(\mathrm{per}-46 \mathrm{HU})$ & 2.12 & [1.630-2.751] & & & 1.43 & [1.031-1.971] \\
\hline$\geq 1$ prevalent VF (vs none) & 4.51 & {$[2.490-8.158]$} & 3.06 & {$[1.450-6.473]$} & 2.47 & [1.128-5.403] \\
\hline Emphysema (vs “no emphysema”) & 2.32 & {$[1.460-3.671]$} & - & & - & \\
\hline
\end{tabular}

Significant ORs are in italic format. For continuous variables, ORs are given per standard deviation of the total population. Multivariate: confounders included according to $>5 \%$ rule (age, sex, and presence of COPD were included in all models). Reference group is the zero Agatston score group OR odds ratio, $95 \%$ CI 95\% confidence interval, BMI body mass index, COPD chronic obstructive pulmonary disease, $B A$ bone attenuation, $H U$ Hounsfield units, $V F$ vertebral fracture, \%LAA \% low attenuation area

\section{Association between baseline Agatston score and incident VFs within 1 and 3 years}

There were 57 subjects $(9.7 \%)$ with incident VFs within 1 year and 137 (23.4\%) within 3 years after baseline (Table 1). Of the subjects with one or more incident VFs within 3 years, 40 (29.2\%) had zero Agatston score, 60 (43.8\%) had medium Agatston score, and 37 (27\%) had high Agatston score (Table 4). In subjects without incident VFs, these numbers were $156(35 \%), 206(46 \%)$, and 87 (19\%) respectively (Supplemental Figure 2).

In univariate models, subjects with high prevalent Agatston score had a significantly increased risk of 1-year VF incidence $(\mathrm{HR}=2.37$ [1.21-4.66]), but of the higher 3-year incidence risk was not significant $(\mathrm{HR}=1.46$ [0.94-2.29]). In multivariate models, subjects with medium or high prevalent Agatston score had no significantly increased VFs risk and this was mainly due to the effect of adding prevalent VFs, age, and BA to the model. However, subjects with a prevalent VF and, in case of 3-year incidence, also subjects with lower $\mathrm{BA}$ had increased risk of $\mathrm{VF}$ incidence.

When the number of incident VFs $(0,1$, or $\geq 2)$ was taken as outcome measure, there were significant univariate associations between subjects with high Agatston score and $\geq 2$ incident VFs (1-year OR $=9.72$ [2.11-44.72]; 3-year OR $=3.79$ [1.64-8.73]), but in multivariate models, this was no longer significant.

\section{Discussion}

In this study, we found an association between prevalent VFs and high Agatston score on chest CT scans in (former) smokers with and without COPD. Associations between Agatston score and incident VFs were not significant in multivariate models. The clinical consequence is that when chest CT scans are performed in (former) smokers to evaluate pulmonary function, supplementary evaluation of the presence of VFs and the degree of CAC gives information on risk factors for other diseases for which additional treatment can be considered.

In line with an earlier review [9], we found significant independent associations between BA, prevalent VFs, and high Agatston score. An association between VFs and Agatston score is consistent with the reported correlation of FRAX-estimated risk of hip fracture or major osteoporotic 


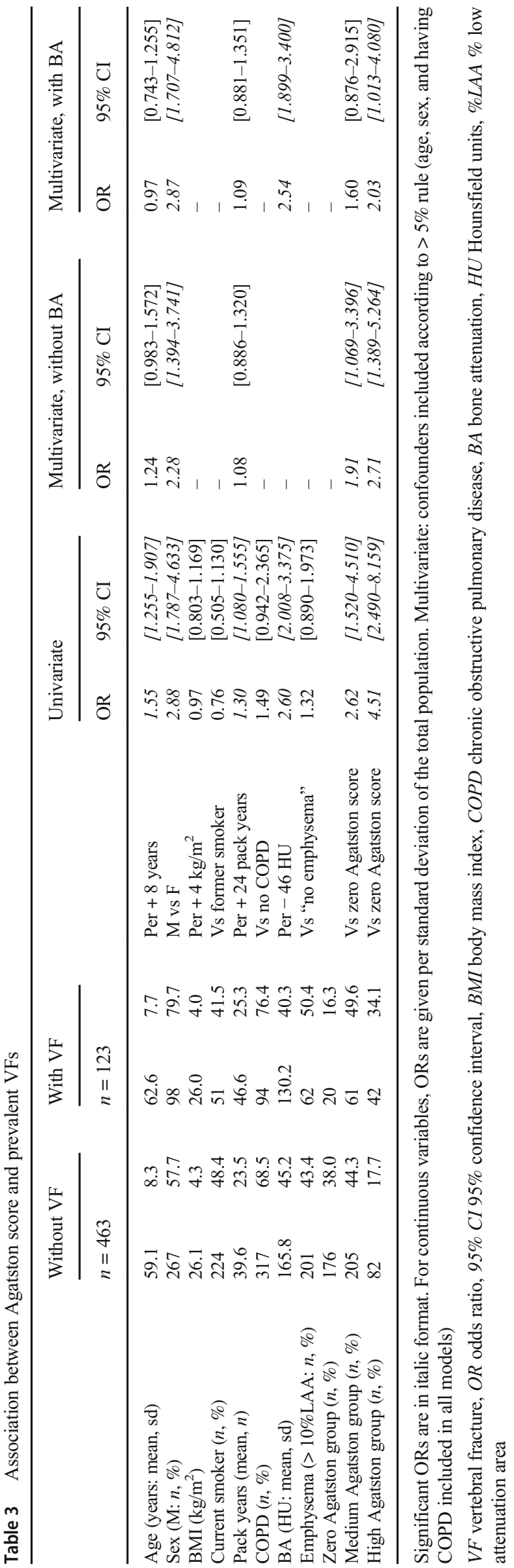

fracture with CAC score [38]. Some linking mechanisms have been proposed, such as an association between micro- and macro-vessel damage and altered microarchitectural indices in the radius [39], or between decreased vascular flow in the lower extremities and increased rate of bone loss at the hip and calcaneus in older women [40]. We suggest that the association between CAC and VFs in part may be explained by the shared risk factor of smoking.

Vascular calcifications in the aorta are commonly seen in patients with osteoporosis, and both increase with aging and with renal disease. Possibly related to renal disease, vascular smooth muscle cells can secrete inhibitors of wnt-signalling that lower bone formation rates. It has been postulated that low bone formation rates fail to buffer high mineral loads and could thus predispose to vascular calcification.

Current smokers had lower odds of having a medium (Table 2; OR $=0.58[0.40-0.85])$ or a high $(\mathrm{OR}=0.50$ [0.32-0.79]) Agatston score compared to former smokers. This may seem unexpected, but in this population, former smokers were significantly older $(62.3 \pm 7.1$ vs $57.0 \pm 8.7)$, more often had COPD (84.9\% vs 53.5\%), and had lower BA $(154.0 \pm 45.3$ vs $163.2 \pm 47.4)$ as compared to current smokers.

There were relatively fewer women $(n=221)$ than men $(n$ $=365$ ) included in this study. A lower percentage of women had a prevalent VF than men in this subcohort $(11.3 \%$ vs $26.8 \%)$, as reported in our previous study ( $14.1 \%$ vs $24.5 \%)$ [8]. In addition, women less often had medium (40.7\%) or high Agatston score (12.7\%) than men (48.2\% and 26.3\% resp.), resulting in very few women with VF and high Agatston score $(n=6(3 \%))$.

When analyses regarding the associations between Agatston score and VFs were performed for men and women separately, the associations for men were similar as presented. However, the associations in women were not significant, not surprisingly given the small number of women in the high risk group. However, it is possible that the women included in this study do not represent the female COPD and smoker population (selection bias) and/or that the association between CAC and VFs is different in men and women.

The literature has been contradictory about the association between emphysema and CACS; some studies found an association between emphysema and CAC $[12,13]$, while others did not [14-16]. Although we found a univariate association between emphysema and medium or high Agatston score (Table 2), this association was not significant after adjustment for age and sex.

Although there was a significant univariate association between high Agatston score and 1-year incidence, and between high Agatston score and $\geq 2$ incident VFs within 1 and 3 years, we did not find any significant multivariate associations between Agatston score and incident VFs after adjusting for age, sex, BA, and prevalent VFs. 
Table 4 Association between Agatston score group and incident VFs

\begin{tabular}{|c|c|c|c|c|c|c|}
\hline & \multicolumn{2}{|c|}{ Univariate } & \multicolumn{2}{|c|}{ Multivariate, without BA } & \multicolumn{2}{|c|}{ Multivariate, with BA } \\
\hline & $\mathrm{HR}$ & $95 \% \mathrm{CI}$ & $\mathrm{HR}$ & $95 \% \mathrm{CI}$ & HR & $95 \% \mathrm{CI}$ \\
\hline \multicolumn{7}{|l|}{ One-year incidence } \\
\hline Age (per +8 years) & 1.49 & {$[1.129-1.954]$} & 1.25 & {$[0.897-1.737]$} & 1.17 & {$[0.827-1.645]$} \\
\hline Sex (M vs F) & 2.05 & {$[1.107-3.815]$} & 1.43 & {$[0.738-2.749]$} & 1.46 & {$[0.757-2.831]$} \\
\hline $\mathrm{BMI}\left(\right.$ per $\left.+4 \mathrm{~kg} / \mathrm{m}^{2}\right)$ & 0.84 & {$[0.652-1.082]$} & 0.90 & {$[0.690-1.177]$} & 0.96 & {$[0.726-1.269]$} \\
\hline Current smoker (vs former) & 0.95 & {$[0.561-1.592]$} & 1.28 & {$[0.716-2.296]$} & 1.32 & {$[0.736-2.367]$} \\
\hline Pack years (per +24 pack years) & 1.21 & {$[0.977-1.489]$} & 1.07 & {$[0.825-1.379]$} & 1.07 & {$[0.827-1.382]$} \\
\hline COPD (vs no COPD) & 1.78 & {$[0.925-3.446]$} & 0.86 & {$[0.352-2.077]$} & 0.87 & {$[0.357-2.106]$} \\
\hline Emphysema ( $>10 \%$ LAA, vs $\leq 10 \%$ LAA) & 2.11 & {$[1.234-3.620]$} & 1.89 & {$[0.936-3.805]$} & 1.85 & {$[0.913-3.740]$} \\
\hline BA (per - $46 \mathrm{HU})$ & 1.79 & {$[1.337-2.395]$} & & & 1.27 & {$[0.910-1.785]$} \\
\hline$\geq 1$ prevalent VF (vs none) & 3.93 & {$[2.338-6.607]$} & 3.19 & {$[1.830-5.553]$} & 2.75 & [1.523-4.970] \\
\hline Medium Agatston score (vs zero) & 1.16 & {$[0.595-2.272]$} & 0.69 & {$[0.335-1.425]$} & 0.67 & {$[0.323-1.373]$} \\
\hline High Agatston score (vs zero) & 2.37 & {$[1.206-4.662]$} & 1.05 & {$[0.481-2.279]$} & 0.97 & {$[0.444-2.130]$} \\
\hline \multicolumn{7}{|l|}{ Three-year incidence } \\
\hline Age (per +8 years $)$ & 1.24 & {$[1.046-1.466]$} & 1.12 & {$[0.916-1.378]$} & 1.05 & {$[0.847-1.297]$} \\
\hline Sex (M vs F) & 1.70 & {$[1.161-2.484]$} & 1.33 & {$[0.890-1.998]$} & 1.37 & {$[0.915-2.060]$} \\
\hline BMI $\left(\right.$ per $\left.+4 \mathrm{~kg} / \mathrm{m}^{2}\right)$ & 0.92 & {$[0.784-1.080]$} & 0.97 & {$[0.817-1.152]$} & 1.03 & {$[0.859-1.226]$} \\
\hline Current smoker (vs former) & 1.11 & {$[0.798-1.558]$} & 1.37 & {$[0.939-2.006]$} & 1.40 & {$[0.956-2.039]$} \\
\hline Pack years (per +24 pack years) & 1.09 & {$[0.939-1.274]$} & 0.97 & {$[0.811-1.165]$} & 0.98 & {$[0.816-1.173]$} \\
\hline COPD (vs no COPD) & 1.40 & {$[0.940-2.075]$} & 1.15 & {$[0.686-1.931]$} & 1.16 & {$[0.690-1.939]$} \\
\hline Emphysema (> 10\%LAA, vs $\leq 10 \%$ LAA) & 0.74 & {$[0.526-1.028]$} & 1.24 & {$[0.812-1.891]$} & 1.22 & {$[0.796-1.862]$} \\
\hline $\mathrm{BA}(\mathrm{per}-46 \mathrm{HU})$ & 1.56 & {$[1.302-1.878]$} & & & 1.29 & [1.034-1.598] \\
\hline$\geq 1$ prevalent VF (vs none) & 3.50 & [2.503-4.892] & 3.30 & {$[2.307-4.713]$} & 2.84 & [1.944-4.152] \\
\hline Medium Agatston score (vs zero) & 1.11 & {$[0.741-1.649]$} & 0.76 & {$[0.494-1.180]$} & 0.73 & [0.472-1.129] \\
\hline High Agatston score (vs zero) & 1.46 & {$[0.935-2.287]$} & 0.80 & {$[0.479-1.335]$} & 0.74 & {$[0.441-1.241]$} \\
\hline
\end{tabular}

Significant HRs are in italic format. For continuous variables, HRs are given per standard deviation of the total population. Multivariate: confounders included according to $>5 \%$ rule (age, sex, and having COPD included in all models)

$V F$ vertebral fracture, $H R$ hazard ratio, $95 \%$ CI 95\% confidence interval, BMI body mass index, COPD chronic obstructive pulmonary disease, $\% L A A \%$ low attenuation area, $B A$ bone attenuation, $H U$ Hounsfield units

A recent meta-analysis examined data from prospective cohort studies of aortic calcification and fractures [41]. Although not all individual studies found significant results, it was reported that subjects in the high aortic calcification category had increased fracture risk compared to subjects in the zero category. However, when types of fractures were specified, Wei et al. reported that the association with incident VFs was not significant, consistent with our findings. They also reported a significant association with incident hip fractures, for which we do not have data. In our results, prevalent VFs (associated with high Agatston score (Tables 2 and 3)) and to a lesser extent baseline BA were significantly associated with incident VFs, also consistent with previous findings [37]. The significant association between high Agatston score and incident VFs disappeared after adjustment. The point estimate shifted towards one which suggests that there is no association between Agatston score measured at baseline and the risk of incident VFs within 1 year. Moreover, there was also no association with incident VFs over 3 years.

In multivariate models, we found an association between prevalent VFs and high Agatston score. Therefore, we suggest all current and former smokers diagnosed with either osteoporosis; a prevalent VF or coronary artery calcification should be evaluated for the osteoporosis or coronary artery disease respectively. Given the relative simplicity of measuring the Agatston score on the chest CTs, we suggest this measurement should be routinely performed and reported and high levels should trigger further assessments including of bone attenuation and coronary artery disease.

There are several limitations in this study.

First, there is a chance of a selection bias due to inclusion of subjects for the ECLIPSE study and selection of subjects from the ECLIPSE study. For the ECLIPSE study, subjects were recruited from outpatient clinics, and subjects with mild COPD 
(GOLD stage I) or who were using oral GC at baseline were excluded. In addition, only non-Hispanic whites were included. From the ECLIPSE study, only subjects with availability of the complete VF assessment [8] and Agatston score evaluation [15] were included for this study. Subjects included $(n=586)$ were somewhat younger, had lower BMI, less often had COPD, more often were current smokers, and less often had emphysema (> $10 \%$ LAA) compared to all ECLIPSE subjects $(n=2298)$. For characteristics of included subjects $(n=586)$ and total ECLIPSE population ( $n=2298$ ), see e-Table 1 , online supplement.

VF data were only available from vertebrae $T_{1}-L_{1}$, so information on prevalent or incident VFs in $\mathrm{L}_{2}-\mathrm{L}_{5}$ is lacking. Also, due to the design of the ECLIPSE study information on other risk factors for fractures, such as the history of falls and fractures, family history of other fractures (including hip fracture), presence of rheumatoid arthritis, or other metabolic disorders were not available and could not be used for adjustment of models for incident VFs. Lastly, Agatston score was only measured at baseline and follow-up data concerning Agatston score are not available.

\section{Conclusion}

In this study of current and former smokers from the ECLIPSE study, we have shown a significant association between prevalent VFs and Agatston score, underlining the concept of multiple comorbidities in this patient group. This indicates that in clinical practice, (former) smokers, who are assessed for and diagnosed with either VF or CAC, should be screened for the other. Since VFs and Agatston score can be diagnosed in CT scans made for pulmonary evaluation, we also recommend opportunistic evaluation of these scans for VFs and CACs as potentially important comorbidities, each of which is amenable to effective interventions.

Funding information This work was financially supported by Stichting De Weijerhorst.

\section{Compliance with ethical standards}

Disclaimer This research was performed independently from funders.

Conflicts of interest Prof. Geusens reports grants, speaker fees and advisory board from Amgen, grants from Pfizer, grants from MSD, grants from UCB, grants from Abbott, grants and speaker fees from Lilly, grants from BMS, grants from Novartis, grants from Roche, and grants from Will Pharma, outside the submitted work. Prof. Eisman reports grants and honoraria from Eli Lilly, Amgen and Merck, outside the submitted work. Prof. Wouters reports board membership at Boehringer, grants and speaker fees from AstraZeneca, grants and speaker fees from GSK, speaker fees from Novartis, and speaker fees from Chiesi, outside the submitted work. Prof. van den Bergh reports grants from Eli Lilly, grants from Will Pharma, and grants from Amgen, outside the submitted work. The rest of the authors have nothing to disclose.
Open Access This article is distributed under the terms of the Creative Commons Attribution-NonCommercial 4.0 International License (http:// creativecommons.org/licenses/by-nc/4.0/), which permits any noncommercial use, distribution, and reproduction in any medium, provided you give appropriate credit to the original author(s) and the source, provide a link to the Creative Commons license, and indicate if changes were made.

\section{References}

1. de Jong WU, de Jong PA, Vliegenthart R, Isgum I, Lammers JW, Oudkerk M, van der Aalst C, de Koning HJ, Mohamed Hoesein FA (2014) Association of chronic obstructive pulmonary disease and smoking status with bone density and vertebral fractures in male lung cancer screening participants. J Bone Miner Res 29:2224 2229

2. Graat-Verboom L, Smeenk FW, van den Borne BE, Spruit MA, Jansen FH, van Enschot JW, Wouters EF (2012) Progression of osteoporosis in patients with COPD: a 3-year follow up study. Respir Med 106:861-870

3. Graat-Verboom L, van den Borne BE, Smeenk FW, Spruit MA, Wouters EF (2011) Osteoporosis in COPD outpatients based on bone mineral density and vertebral fractures. J Bone Miner Res 26:561-568

4. Jaramillo JD, Wilson C, Stinson DS, Lynch DA, Bowler RP, Lutz S, Bon JM, Arnold B, McDonald M, Washko GR, Wan ES, DeMeo D, Foreman MG, Soler X, Lindsay SE, Lane NE, Genant HK, Silverman EK, Hokanson JE, Make BJ, Crapo JD, Regan EA, COPDGene Investigators (2015) Reduced bone density and vertebral fractures in smokers. Men and COPD patients at increased risk. Ann Am Thorac Soc 12:648-656

5. Kjensli A, Falch JA, Ryg M, Blenk T, Armbrecht G, Diep LM, Ellingsen I (2009) High prevalence of vertebral deformities in COPD patients: relationship to disease severity. Eur Respir J 33: 1018-1024

6. Nuti R, Siviero P, Maggi S, Guglielmi G, Caffarelli C, Crepaldi G, Gonnelli S (2009) Vertebral fractures in patients with chronic obstructive pulmonary disease: the EOLO Study. Osteoporos Int 20: 989-998

7. Watanabe R, Tanaka T, Aita K, Hagiya M, Homma T, Yokosuka K, Yamakawa H, Yarita T, Tai N, Hirano J, Inoue D, Okazaki R (2015) Osteoporosis is highly prevalent in Japanese males with chronic obstructive pulmonary disease and is associated with deteriorated pulmonary function. J Bone Miner Metab 33:392-400

8. van Dort MJ, Geusens P, Driessen JH, Romme EA, Smeenk FW, Wouters EF, van den Bergh JP (2018) High imminent vertebral fracture risk in subjects with COPD with a prevalent or incident vertebral fracture. J Bone Miner Res 33(7):1233-1241

9. Laroche M, Pecourneau V, Blain H, Breuil V, Chapurlat R, Cortet B, Sutter B, Degboe Y (2017) Osteoporosis and ischemic cardiovascular disease. Joint Bone Spine 84:427-432

10. Romme EA, Rutten EP, Geusens P, de Jong JJ, van Rietbergen B, Smeenk FW, Wouters EF, van den Bergh JP (2013) Bone stiffness and failure load are related with clinical parameters in men with chronic obstructive pulmonary disease. J Bone Miner Res 28:21862193

11. Bon J, Fuhrman CR, Weissfeld JL, Duncan SR, Branch RA, Chang CC, Zhang Y, Leader JK, Gur D, Greenspan SL, Sciurba FC (2011) Radiographic emphysema predicts low bone mineral density in a tobacco-exposed cohort. Am J Respir Crit Care Med 183:885-890 
12. Chae EJ, Seo JB, Oh YM, Lee JS, Jung Y, Lee SD (2013) Severity of systemic calcified atherosclerosis is associated with airflow limitation and emphysema. J Comput Assist Tomogr 37:743-749

13. O'Hare PE, Ayres JF, O'Rourke RL, Slaughter RE, Marshall HM, Bowman RV, Fong KM, Yang IA (2014) Coronary artery calcification on computed tomography correlates with mortality in chronic obstructive pulmonary disease. J Comput Assist Tomogr 38:753-759

14. Barr RG, Ahmed FS, Carr JJ, Hoffman EA, Jiang R, Kawut SM, Watson K (2012) Subclinical atherosclerosis, airflow obstruction and emphysema: the MESA Lung Study. Eur Respir J 39:846-854

15. Williams MC, Murchison JT, Edwards LD, Agustí A, Bakke P, Calverley PM, Celli B, Coxson HO, Crim C, Lomas DA, Miller BE, Rennard S, Silverman EK, Tal-Singer R, Vestbo J, Wouters E, Yates JC, van Beek E, Newby DE, MacNee W, Evaluation of COPD Longitudinally to Identify Predictive Surrogate Endpoints (ECLIPSE) investigators (2014) Coronary artery calcification is increased in patients with COPD and associated with increased morbidity and mortality. Thorax 69:718-723

16. Romme EA, McAllister DA, Murchison JT, Van Beek EJ, Petrides GS, Price CO, Rutten EP, Smeenk FW, Wouters EF, MacNee W (2013) Associations between COPD related manifestations: a crosssectional study. Respir Res 14:129

17. Coylewright M, Rice K, Budoff MJ, Blumenthal RS, Greenland P, Kronmal R, Barr RG, Burke GL, Tracy R, Post WS (2011) Differentiation of severe coronary artery calcification in the MultiEthnic Study of Atherosclerosis. Atherosclerosis 219:616-622

18. Greenland P, LaBree L, Azen SP, Doherty TM, Detrano RC (2004) Coronary artery calcium score combined with Framingham score for risk prediction in asymptomatic individuals. Jama 291:210-215

19. Polonsky TS, McClelland RL, Jorgensen NW, Bild DE, Burke GL, Guerci AD, Greenland P (2010) Coronary artery calcium score and risk classification for coronary heart disease prediction. Jama 303: $1610-1616$

20. Criqui MH, Denenberg JO, Ix JH, McClelland RL, Wassel CL, Rifkin DE, Carr JJ, Budoff MJ, Allison MA (2014) Calcium density of coronary artery plaque and risk of incident cardiovascular events. Jama 311:271-278

21. Kondos GT, Hoff JA, Sevrukov A, Daviglus ML, Garside DB, Devries SS, Chomka EV, Liu K (2003) Electron-beam tomography coronary artery calcium and cardiac events: a 37-month follow-up of 5635 initially asymptomatic low- to intermediate-risk adults. Circulation 107:2571-2576

22. Budoff MJ, Shaw LJ, Liu ST, Weinstein SR, Mosler TP, Tseng PH, Flores FR, Callister TQ, Raggi P, Berman DS (2007) Long-term prognosis associated with coronary calcification: observations from a registry of 25,253 patients. J Am Coll Cardiol 49:1860-1870

23. Shaw LJ, Giambrone AE, Blaha MJ, Knapper JT, Berman DS, Bellam N, Quyyumi A, Budoff MJ, Callister TQ, Min JK (2015) Long-term prognosis after coronary artery calcification testing in asymptomatic patients: a cohort study. Ann Intern Med 163:14-21

24. Shaw LJ, Raggi P, Schisterman E, Berman DS, Callister TQ (2003) Prognostic value of cardiac risk factors and coronary artery calcium screening for all-cause mortality. Radiology 228:826-833

25. Chiles C, Duan F, Gladish GW, Ravenel JG, Baginski SG, Snyder BS, DeMello S, Desjardins SS, Munden RF (2015) Association of coronary artery calcification and mortality in the National Lung Screening Trial: a comparison of three scoring methods. Radiology 276:82-90

26. Odink AE, van der Lugt A, Hofman A, Hunink MG, Breteler MM, Krestin GP, Witteman JC (2007) Association between calcification in the coronary arteries, aortic arch and carotid arteries: the Rotterdam study. Atherosclerosis 193:408-413

27. Agusti A, Calverley PM, Celli B et al (2010) Characterisation of COPD heterogeneity in the ECLIPSE cohort. Respir Res 11:122

28. Hurst JR, Vestbo J, Anzueto A, Locantore N, Müllerova H, TalSinger R, Miller B, Lomas DA, Agusti A, Macnee W, Calverley P,
Rennard S, Wouters EF, Wedzicha JA, Evaluation of COPD Longitudinally to Identify Predictive Surrogate Endpoints (ECLIPSE) Investigators (2010) Susceptibility to exacerbation in chronic obstructive pulmonary disease. N Engl J Med 363:11281138

29. Vestbo J, Anderson W, Coxson HO, Crim C, Dawber F, Edwards L, Hagan G, Knobil K, Lomas DA, MacNee W, Silverman EK, TalSinger R, ECLIPSE investigators (2008) Evaluation of COPD Longitudinally to Identify Predictive Surrogate End-points (ECLIPSE). Eur Respir J 31:869-873

30. Coxson HO, Dirksen A, Edwards LD, Yates JC, Agusti A, Bakke P, Calverley PM, Celli B, Crim C, Duvoix A, Fauerbach PN, Lomas DA, Macnee W, Mayer RJ, Miller BE, Müller NL, Rennard SI, Silverman EK, Tal-Singer R, Wouters EF, Vestbo J, Evaluation of COPD Longitudinally to Identify Predictive Surrogate Endpoints (ECLIPSE) Investigators (2013) The presence and progression of emphysema in COPD as determined by CT scanning and biomarker expression: a prospective analysis from the ECLIPSE study. Lancet Respir Med 1:129-136

31. Brett A, Miller CG, Hayes CW, Krasnow J, Ozanian T, Abrams K, Block JE, van Kuijk C (2009) Development of a clinical workflow tool to enhance the detection of vertebral fractures: accuracy and precision evaluation. Spine (Phila Pa 1976) 34:2437-2443

32. van der Velde R, Ozanian T, Dumitrescu B, Haslam J, Staal J, Brett A, van den Bergh J, Geusens P (2015) Performance of statistical models of shape and appearance for semiautomatic segmentations of spinal vertebrae T4-L4 on digitized vertebral fracture assessment images. Spine J 15:1248-1254

33. van Dort MJ, Romme E, Smeenk F, Geusens P, Wouters EFM, van den Bergh JP (2018) Diagnosis of vertebral deformities on chest CT and DXA compared to routine lateral thoracic spine X-ray. Osteoporos Int 29(6):1285-1293

34. Genant HK, Wu CY, van Kuijk C, Nevitt MC (1993) Vertebral fracture assessment using a semiquantitative technique. J Bone Miner Res 8:1137-1148

35. Agatston AS, Janowitz WR, Hildner FJ, Zusmer NR, Viamonte M Jr, Detrano R (1990) Quantification of coronary artery calcium using ultrafast computed tomography. J Am Coll Cardiol 15:827832

36. Romme EA, Murchison JT, Edwards LD, van Beek E Jr, Murchison DM, Rutten EP, Smeenk FW, Williams MC, Wouters EF, MacNee W (2013) CT-measured bone attenuation in patients with chronic obstructive pulmonary disease: relation to clinical features and outcomes. J Bone Miner Res 28:1369-1377

37. Lee SJ, Graffy PM, Zea RD, Ziemlewicz TJ, Pickhardt PJ (2018) Future osteoporotic fracture risk related to lumbar vertebral trabecular attenuation measured at routine body CT. J Bone Miner Res 33: 860-867

38. Chuang TL, Li YD, Hsiao FT, Chuang MH, Wang YF (2017) FRAX(R) fracture risks are associated with coronary artery calcification score. Dis Markers 2017:1592598

39. Atlan L, Ibrahim-Nasser N, Valery A, Bazzi C, Rollin F, Bens G, Marot M, Esteve E, Lespessailles E (2018) Bone mineral density and microarchitecture linkages with micro- and macro-vascular impairments at the hand in systemic sclerosis: an HRpQCT study. Oncotarget 9:29484-29494

40. Vogt MT, Cauley JA, Kuller LH, Nevitt MC (1997) Bone mineral density and blood flow to the lower extremities: the study of osteoporotic fractures. J Bone Miner Res 12:283-289

41. Wei D, Zheng G, Gao Y, Guo J, Zhang T (2018) Abdominal aortic calcification and the risk of bone fractures: a meta-analysis of prospective cohort studies. J Bone Miner Metab 36:439-446

Publisher's note Springer Nature remains neutral with regard to jurisdictional claims in published maps and institutional affiliations. 